Gut, 1989, 30, 305-310

\title{
Acid perfusion test: Does it have a role in the assessment of non cardiac chest pain?
}

\author{
E G HEWSON, J W SINCLAIR, C B DALTON, W C WU, D O CASTELL, \\ AND J E RICHTER
}

From the Bowman Gray School of Medicine, Winston-Salem, North Carolina, USA

SUMMARY Using 24 hour pH monitoring as a reference standard, the usefulness of the acid perfusion (AP) test in predicting gastro-oesophageal reflux disease (GORD) was assessed in 71 noncardiac chest pain (NCCP) patients and 23 endoscopic oesophagitis patients. Of the 71 NCCP patients, 35 had a positive AP test (of whom 20 had an abnormal 24 hour pH) and 36 had a negative AP test (of whom 14 had an abnormal 24 hour pH study). Thus, the sensitivity, specificity, positive predictive value (PPV) and negative predictive value (NPV) of the AP test in this group was 59\%, $59 \%, 57 \%$, and $\mathbf{6 1 \%}$, respectively. The corresponding values in the oesophagitis group were $85 \%$, $67 \%, 94 \%$, and $40 \%$. In the NCCP group when heartburn alone was used as the positive criterion the PPV rose to $74 \%$. When chest pain with or without heartburn was used, however, the PPV dropped to $38 \%$. A 'symptom index' was used to define the number of chest pain episodes that were caused by acid reflux. Only $48 \%$ of AP test positive patients had demonstrable acid mediated chest pain. In the NCCP population with a normal oesophageal examination (1) AP test reproduction of chest pain is poorly predictive of GORD; (2) AP test reproduction of heartburn is more predictive of GORD but does not ensure that the chest pain is caused by GORD; (3) a negative AP test does not exclude GORD and (4) only $48 \%$ of AP test positive patients have demonstrable acid mediated chest pain. The ambulatory 24 hour pH test may have rendered the AP test obsolete in the assessment of GORD as the cause of NCCP.

Since its introduction 30 years ago, the acid perfusion (AP) test has gained wide acceptance. As originally described, the test was designed to assess whether chest pain or heartburn was secondary to increased oesophageal sensitivity to acid. In more recent times, the AP test has been widely used as a screening test for possible gastro-oesophageal reflux disease (GORD) in patients with non-cardiac chest pain (NCCP) and a radiologically or endoscopically normal oesophagus. The sensitivity (41-100\%) and specificity $(50-100 \%)$ of the test has, however, varied markedly.' These disparate results may be related to differences in patient populations, variations in the performance and interpretation of the

Address for correspondence: Joel E Richter, MD, Section of Gastroenterology. Bowman Gray School of Medicine, 300 S Hawthorne Road, Winston-Salem. North Carolina 27103, USA.

Accepted for publication 11 August 1988. test, and differing 'gold standards' used to define GORD.

At present the ambulatory 24 hour $\mathrm{pH}$ test is the most reliable method for the diagnosis of GORD. The test is labour intensive, however, requires expensive equipment, and may be uncomfortable for the patient. In contrast, the AP test is cheap and rapidly carried out. A comparison of the two tests has never been done. Therefore, our goal was to review the usefulness of the AP test in predicting GORD by comparing it with 24 hour $\mathrm{pH}$ monitoring in NCCP patients with a normal oesophageal examination. Patients with erosive or ulcerative oesophagitis having both tests served as our comparison group.

Methods

PATIENT POPULATIONS

We retrospectively reviewed patient records for the 
preceding 30 months. Group A comprised 71 patients with non-cardiac chest pain ( $29 \mathrm{M}, 42 \mathrm{~F}$; mean age 46.7 years, range 20 to 75 years) who had undergone both an AP test and 24 hour $\mathrm{pH}$ test as part of their evaluation. All patients were evaluated by staff cardiologists who excluded significant coronary artery disease. The majority of patients $(72 \%)$ had coronary angiography. All patients had a grossly normal examination of the oesophagus either by endoscopy or barium studies. Group B comprised 23 patients $(12 \mathrm{M}, 11 \mathrm{~F}$; mean age $39 \cdot 0$ years, range 24 to 72 years) with endoscopic evidence of erosive or ulcerative oesophagitis who were being evaluated as part of a drug study. All suffered from frequent heartburn, but none complained of chest pain. Patients with Barrett's oesophagus, oesophageal stricture and scleroderma were excluded from this study group.

\section{ACID PERFUSION TEST}

The oesophageal AP test was done immediately after standard oesophageal manometry with the patient remaining in the supine position. ${ }^{2}$ A separate manometry port $6 \mathrm{~cm}$ above the lower oesophageal sphincter was used to infuse normal saline at a rate of $7 \mathrm{ml} /$ minute for two minutes. Without the patients knowledge, the solution was then switched to $0 \cdot 1 \mathrm{~N}$ hydrochloric acid infused at a similar rate for 10 minutes. Lack of symptom reproduction after acid infusion constituted a negative AP test. If symptoms (either hearburn and/or chest pain) were reproduced after acid, normal saline was again infused for 10 minutes or until symptoms eased, at which time the acid infusion was repeated. For the purpose of this study, a positive test occurred when the patients typical chest pain, and/or heartburn, were twice reproduced during acid infusion.

To ensure that the results of our modified AP test were comparable with the originally described test, 41 asymptomatic volunteers were used as a control group $(23 \mathrm{~F}, 18 \mathrm{M}$; mean age 54.6 years, range $32-74$ years). Controls were excluded if they suffered from heartburn more than once per month or had ever noticed regurgitation, dysphagia or chest pain.

Table 1 Statistical methods

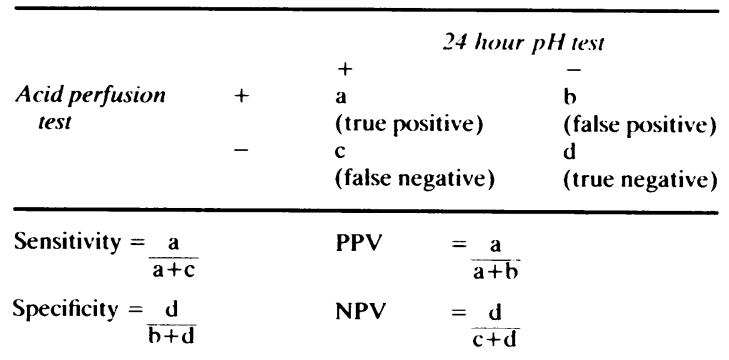

Similary subjects with any evidence of alcohol abuse, known diabetes, collagen vascular disease or neurological disorders were also excluded. Three of the 41 asymptomatic volunteers $(7 \%)$ had a positive AP test for heartburn but none noted chest pain. These results are difficult to interpret in the absence of a 24 hour $\mathrm{pH}$ test but are similar to the original study by Bernstein and Baker, and other reports, that found positive rates ranging from 5 to $15 \%$ in volunteer subjects. ${ }^{\text {.h }}$

\section{HOUR OESOPHAGEAL PH TEST}

One of two systems were used: the Sandhill system (Sandhill, Littleton, Colorado) uses an antimony electrode with a $3.0 \mathrm{~mm}$ outer diameter, or the DelMar system (DelMar Avionics, Irvine, California) which uses a glass electrode with a $1.8 \mathrm{~mm}$ outer diameter. Both systems are calibrated at body temperature $\left(37^{\circ} \mathrm{C}\right)$ before and after each study and both ultilise reference electrodes attached to the anterior chest. The probe was passed through the nose and positioned $5 \mathrm{~cm}$ above the manometrically determined lower oesophageal sphincter. Patients were given a standard diet sheet and instructed to avoid food or drink with a $\mathrm{pH}<5$. Alcohol and smoking were allowed. Meals, chest pain events, and other symptoms of interest were noted on a written diary card and recorded via an event marker on the $\mathrm{pH}$ monitor. Acid exposure times and reflux episodes were scored and tabulated by computer for upright, recumbent and total study time.

All tracings were inspected by one of the authors to confirm the computerised calculations and to ensure the quality of the recordings. A drop of $\mathrm{pH}$ below 4.0 was considered evidence of GOR. ${ }^{7}$ The end of a reflux episode was defined as the point at which the $\mathrm{pH}$ had risen from below 4 and remained above that $\mathrm{pH}$ value for at least six seconds. Previous studies in our laboratory suggested that the most reproducible 24 hour pH test parameters are per cent time with pH below 4 in the upright and recumbent position as well as total time. ${ }^{*}$ Therefore, GORD was defined as present if any of these three parameters exceeded normal values obtained by studying 20 healthy volunteers (eight $\mathrm{M}, 12 \mathrm{~F}$; mean age 31 years) upright time $>5.6 \%$, recumbent time $>1.62 \%$, total time $>4.02 \%$.

A subgroup of patients have recently been identified who, despite a normal 24 hour pH test, have chest pain events temporaly associated with acid reflux episodes. To assess the prevalence of reflux mediated chest pain events, we calculated a 'symptom index" in patients with normal and abnormal 24 hour acid exposure. This index used the following formula: number of chest pain events occuring when $\mathrm{pH}$ was below 4 divided by the total number of chest pain 
events reported. This quotient was then multiplied by 100 to give the percentage of chest pain events associated with reflux. A chest pain event was defined as secondary to a reflux episode if the oesophageal $\mathrm{pH}$ dropped below 4 for longer than 30 seconds and occurred up to five minutes before the onset of chest pain. For this study, the symptom index was arbitrarily defined as significant if a score of greater than $25 \%$ was achieved - that is, greater than one episode in four of chest pain associated with acid reflux.

\section{STATISTICAL ANALYSIS}

For both the non-cardiac chest pain and oesophagitis patients, the sensitivity, specificity, positive predictive value (PPV), and negative predictive value (NPV) were calculated comparing the AP test to the 24 hour $\mathrm{pH}$ test used as the reference standard (Table 1). Sensitivity was defined as the number of true positive cases divided by the total number of confirmed positive cases. Specificity was defined as the number of true negative cases divided by the total number of confirmed negative cases. In clinical practice, however, it is the predictive accuracy of a test that is important to the clinician when presented with a normal or abnormal test result. Thus, positive predictive value (PPV) is an index of how often a test is correct when its result is positive. Negative predictive value (NPV) is an index of negative accuracy for the correctness of negative results. It must be remembered that predictive values are influenced by the prevalence of the studied condition. Therefore, positive results more accurately predict disease when the disease prevalence is high, while negative results under the same circumstances poorly predict the absence of disease."'

\section{Results}

\section{ACID PERFUSION TEST}

Thirty five of 71 NCCP patients $(49 \%)$ had positive AP tests defined as reproduction of typical chest pain and/or heartburn during acid infusion (19 heartburn alone; nine chest pain alone; seven chest pain plus heartburn). Eighteen of the 23 oesophagitis patients

Table 2 Overall results

\begin{tabular}{|c|c|c|c|c|c|}
\hline & $\begin{array}{l}\text { Patients } \\
\text { (n) }\end{array}$ & Sens $(\%)$ & Spec (\%) & $P P V(\%)$ & $N P V(\%)$ \\
\hline $\begin{array}{l}\text { NCCP } \\
\mathrm{EE}\end{array}$ & $\begin{array}{l}71 \\
23\end{array}$ & $\begin{array}{l}20 / 34(59 \%) \\
17 / 20(85 \%)\end{array}$ & $22 / 37(59 \%)$ & $20 / 35(57 \%)$ & ) $22 / 36(61 \%)$ \\
\hline EE & 23 & $17 / 20(85 \%)$ & $2 / 3(66 \%)$ & $17 / 18(94 \%)$ & $2 / 5(40 \%)$ \\
\hline
\end{tabular}

Overall results in the NCCP and endoscopic oesophagitis (EE) groups. Actual patient numbers are shown. Calculations performed as described in Table 1.
(78\%) had positive AP tests for heartburn. No patient in the oesophagitis group noted chest pain during intraoesophageal acid infusion.

\section{HOUR PH RESULTS}

Thirty six of $71(51 \%)$ NCCP patients and 20 of 23 (87\%) oesophagitis patients had abnormal 24 hour $\mathrm{pH}$ results.

CORRELATION BETWEEN ACID PERFUSION TEST AND 24 HOUR PH RESULTS

Only 20 of the 35 NCCP patients (57\%) with positive AP tests had abnormal 24 hour pH tests. Conversely, 14 of the 36 patients (39\%) with negative AP tests had abnormal 24 hour $\mathrm{pH}$ studies. Therefore, as shown in Table 2, the sensitivity, specificity, positive predictive value (PPV), and negative predictive value (NPV) of the AP test to identify GORD, with the 24 hour $\mathrm{pH}$ test as the reference standard, only approximates $60 \%$ in this population of patients.

When chest pain or heartburn are used as the criterion for a positive AP test, only positive predictive value can be calculated. This is because of the inherent flaw in determining what can be counted as a negative AP test when only one or other criteria of chest pain or heartburn are used as end points. When heartburn alone is used, the PPV is $74 \%$; when chest pain with or without heartburn is used, the PPV drops dramatically to $38 \%$ (Table 3 ). It must be noted that the 'gold standard' in this situation denotes only abnormal 24 hour acid exposure, not chest pain association with reflux episodes.

The AP test was more reliable in the patients with endoscopic oesophagitis (Tables 2, 3). Both sensitivity and positive predictive value were high $(85 \%$ and $94 \%$, respectively) while the lower specificity $(67 \%)$ and negative predictive value $(40 \%)$, may have been distorted by the small numbers of patients with a negative test.

ASSOCIATION OF SYMPTOM INDEX, ACID PERFUSION TEST AND 24 HOUR PH STUDIES

Four of the 35 patients with positive AP tests did not have chest pain during the 24 hour $\mathrm{pH}$ test. Therefore, a symptom index was calculated only for the remaining 31 patients (Table 4). Sixteen patients had chest pain (with or without heartburn) after acid infusion. Six patients had a positive symptom index, three of whom had normal 24 hour exposure. Ten patients had a negative symptom index - that is, no correlation of acid reflux with chest pain during the 24 hour study. Interestingly, three of the 10 had abnormal 24 hour acid exposure (Table 4). Thus, seven of 16 patients with positive AP tests for chest pain had both a negative symptom index and a normal 24 hour $\mathrm{pH}$ study. 
Table 3 Positive predictive value of the acid perfusion test

\begin{tabular}{cccc}
\hline & $-G O R$ & $-G O R$ & $P P V$ \\
\hline i + AP (HB or CP) & 20 & 15 & $57 \%$ \\
- AP (HB or CP) & 14 & 22 & \\
ii + AP (HB alone) & 14 & 5 & $74 \%$ \\
iii + AP (CP \pm HB) & 6 & 10 & $38 \%$ \\
iv + AP (HB alone) & 17 & 1 & $94 \%$ \\
- AP (HB alone) & 3 & 2 & \\
\hline
\end{tabular}

i-iii denotes NCCP patients. iv denotes endoscopic esophagitis patients. Actual patient numbers are shown. $+\mathrm{AP}=$ positive acid perfusion test. $-\mathrm{AP}=$ negative acid perfusion. $\mathrm{CP}=$ chest pain. $\mathrm{HB}=$ heartburn $\mathrm{CP} \pm \mathrm{HB}=$ chest pain, with or without heartburn.

Results were somewhat more encouraging for those 15 patients with positive AP tests for heartburn alone. Nine of 15 had a positive symptom index. Seven of these nine patients had abnormal 24 hour acid exposure (Table 4). Six patients had a negative symptom index, but three of these had abnormal 24 hour exposure. As a group, only three of the 15 patients with a positive AP test for heartburn alone, had both a negative symptom index and a normal 24 hour $\mathrm{pH}$ study.

The AP test was then compared directly with the symptom index. Unfortunately, the results were disappointing. Of the 16 patients with positive AP tests for chest pain (with or without heartburn), six had a symptom index of greater than $25 \%$. The remaining 10 patients had a symptom index less than $25 \%$. Of the 15 patients with positive AP tests for heartburn alone, nine had a symptom index greater than $25 \%$ while six had a symptom index of less than $25 \%$. Thus, only $48 \%$ of the AP test positive patients had demonstrable acid mediated chest pain (Table 4).

\section{Discussion}

Described in 1958 by Bernstein and Baker, the AP test was originally designed to 'objectively' show the relationship of acid to oesophageal symptoms, and hopefully differentiate oesophageal from cardiac chest pain. ${ }^{3}$ In particular, it was felt the test would provide 'substantiating objectivity to conclusions attributing symptoms to a normal appearing oesophagus' - that is, that heartburn and chest pain were oesophageal in origin. Has the AP test lived up to these expectations? What role does it have in the evaluation of oesophageal disease?

Five years ago, Richter $^{1}$ reviewed seven series assessing the reliability of the AP test as a screening study for GORD. Overall, a sensitivity of $77 \%$ (range 41 to $100 \%$ ) and specificity of $86 \%$ (range 50 to $100 \%$ ) was found. These series evaluated different patient populations, however, and different
Table 4 Acid perfusion test, 24 hour pH test, and symptom index in NCCP patients

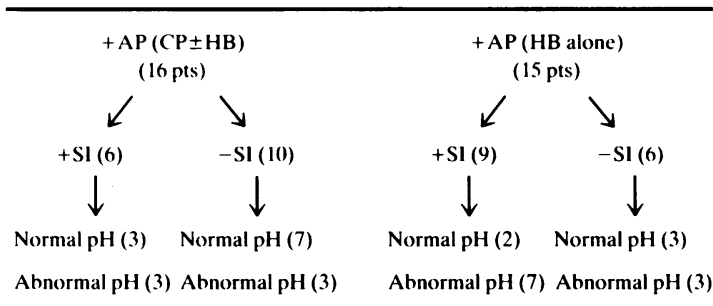

$+\mathrm{AP}=$ positive acid perfusion test. $-\mathrm{AP}=$ negative acid perfusion. $\mathrm{CP}=$ chest pain. $\mathrm{HB}=$ heartburn. $+\mathrm{SI}=$ positive symptom index. $-\mathrm{SI}=$ negative symptom index. Actual patient numbers are in parenthesis.

parameters were used to define GORD. In particular, most series did not separate the results obtained from patient with macroscopically normal versus abnormal oesophageal mucosa. This has clinical importance as most patients with macroscopic oesophagitis do not have, and indeed do not require, an AP test for confirmation of acid sensitivity as a cause of their symptoms. Those patients with atypical reflux symptoms or non-cardiac chest pain, however, who have a normal appearing oesophagus often undergo an AP test. It is in these patients that we want to be confident that a positive test indicates acid reflux as a cause of the patient's complaints.

The ambulatory 24 hour $\mathrm{pH}$ test is recognised as having high sensitivity and specificity for the diagnosis of GOR. Patients are tested in their home environment. A distinct advantage is that it permits correlation of symptoms with acid reflux episodes. Although requiring expensive equipment and being time consuming, the 24 hour $\mathrm{pH}$ test is widely available and utilised. A study of its usefulness compared with the AP test, an older 'gold standard,' was warranted.

Our results suggest that confidence may be misplaced in the ability of the AP test to diagnose GOR in patients with NCCP and a normal endoscopic or radiologic oesophageal examination. When either heartburn or chest pain is defined as a positive response, the AP test has a sensitivity of $59 \%$, specificity of $59 \%$, and a positive predictive value of $57 \%$. Even more disturbing, the positive predictive value drops to $38 \%$ when chest pain is used as a positive criterion. Are there inherent problems with the test itself; or do these poor results mean we are asking the wrong question of the test?

Undoubtedly, the AP test has several problems. (1) The recognition of chest pain or heartburn during acid reflux is a subjective response with wide perceptional variability. Symptomatically silent reflux occurs commonly in healthy subjects.? Conversely, 
patients with severe GORD and Barrett's oesophagus may be acid insensitive in up to onethird of cases." (2) False-positive results have been reported in patients with duodenal ulcers and gastritis as well as in normal subjects. ${ }^{5612}$ (3) The length of oesophageal acid exposure time influences the AP test results. Two groups showed increased sensitivity but reduced specificity when the acid infusion time was increased from five minutes to 30 minutes. ${ }^{413}$ (4) The AP test does not consider the effects of endogenous substances such as bile, pepsin, or pancreatic enzymes, in the production of reflux symptoms. (5) The AP test cannot possibly reproduce the wide variety of exogenous substances that may damage or irritate the oesophageal mucosa - for example, cigarette smoke, alcohol, or hyperosmolar substances. Thus, the AP test has many potential sources of error.

Are we asking the wrong question of the test? The original use of the AP test was to measure oesophageal acid sensitivity, not to define the presence or absence of GOR. The symptom index attempts to measure acid reflux mediated chest pain events that occur independent of the total acid reflux time. Perhaps comparison of the symptom index with the AP test is a more appropriate measure of the latters validity. Unfortunately, the AP test is still found wanting. Only $48 \%$ of our NCCP population who had chest pain during their 24 hour monitoring period had an association between their symptom index and a positive AP test.

A note of caution is warranted. Perhaps the 24 hour $\mathrm{pH}$ test should be regarded more as a 'silver' rather than a 'gold' standard. The test has limitations. The amount of acid reflux varies from day to day. ${ }^{14}$ It has been found recently that the oesophageal probe may miss episodes of reflux possibly because of its being imbedded in redundant mucosa. ${ }^{15}$ The $\mathrm{pH}$ probe is unable to measure the volume of reflux, although the importance of this parameter is presently unclear. Furthermore, certain dietary restrictions are used to standardise the 24 hour $\mathrm{pH}$ test, and these may contribute to underestimation of GOR. Despite these limitations, recent reproducibility data suggest a concordance rate of $85-90 \%$ between studies..$^{14}$ Also, chest pain events caused by acid reflux, as defined by the 24 hour $\mathrm{pH}$ study, predict the response to medical or surgical therapy. ${ }^{16}$

Other possible confounding factors can be quickly dismissed. If oesophageal acid infusion causes chest pain by inducing a motility disorder, then this could not be measured by the 24 hour $\mathrm{pH}$ monitor. Numerous studies ${ }^{21-19}$ have shown, however, that acid induced chest pain is rarely the result of abnormal motility alone. Second, it is known that oesophageal distention may cause heartburn and chest pain. ${ }^{20}$ In fact, this may explain some of the low symptom index results. It has been shown, however, that infusion of acid at $7 \mathrm{ml} / \mathrm{min}$ does not lead to distention of the oesophagus. ${ }^{21}$

Seven patients, nearly $10 \%$ of the NCCP population studied, had their chest pain reproduced during the AP test, yet had a normal 24 hour $\mathrm{pH}$ test and a negative symptom index. Could the AP test be identifying a further subpopulation of patients with acid mediated chest pain - that is, do these patients form part of the spectrum of the irritable oesophagus? ${ }^{22}$ One possible way to answer the former question may be to enter these patients into a placebo controlled trial using a powerful antisecretory drug, such as omeprazole, and assess their response. Such a trial should be done before the AP test is totally dismissed.

The AP test should have its greatest application in the non-cardiac chest pain population with a normal appearing oesophagus. Unfortunately, our data suggest that it is a poor screening study for GORD, especially if chest pain is used as a positive criterion. Heartburn during acid infusion may be more suggestive of GORD, but still does not ensure that the patient's chest pain is of oesophageal origin. Unfortunately, a negative AP test does not exclude GORD. Thus, the AP test has poor sensitivity, specificity and predictive value for the diagnosis of GORD. The lack of correlation between the symptom index and AP test also is disappointing. This may reflect both the artificial nature of the AP test, however, and the presence of cofactors that cannot be reproduced during this laboratory test. We believe ambulatory oesophageal 24 hour $\mathrm{pH}$ monitoring has rendered the AP test obsolete in the assessment of gastro-oesophageal reflux as a cause of non-cardiac chest pain.

We wish to thank Kathy Myers for the excellent secretarial assistance and extraordinary patience. This work has been published in abstract form in Gastroenterology 1988; 94: 184A.

\section{References}

1 Richter JE. Acid perfusion (Bernstein) test. In: Castell DO, Wu WC, Ott DJ, eds. Gastroesophageal reflux disease. Pathogenesis, diagnosis and therapy. Mount Kesco, NY: Futura Publishing Co Inc, 1985: 139-48.

2 Richter JE, Johns DN, Wu WC, Castell DO. Are esophageal motility abnormalities produced during the intraesophageal acid perfusion test? JAMA 1985; 253: 1914-7.

3 Bernstein LM, Baker LA. A clinical test for esophagitis. Gastroenterology 1958; 34: 760-81. 
4 Bennett JR, Atkinson M. Oesophageal acid-perfusion in the diagnosis of precordial pain. Lancet 1966; ii: 1150-2.

5 Benz LJ, Hootkin LA, Margulies S, Donner MW, Cauthorne RT, Hendrix TR. A comparison of clinical measurements of gastroesophageal reflux. Gastroenterology 1972; 62: 1-5.

6 Behar J, Biancini P, Sheahan DG. Evaluation of esophageal tests in the diagnosis of reflux esophagitis. Gastroenterology 1976; 71: 9-15.

7 Johnson LF, DeMeester TR. Twenty-four hour $\mathrm{pH}$ monitoring of the distal esophagus: A quantitative measure of gastroesophageal reflux. Am J Gastroenterol 1974; 62: 325-32.

8 Ward BW, Wu WC, Richter JE, Lui KW, Castell DO. Ambulatory 24-hour esophageal $\mathrm{pH}$ monitoring. Technology searching for a clinical application. $J$ Clin Gastroenterol 1986; 8 [suppl 1]: 59-67.

9 Wiener GJ, Richter JE, Copper JB, Wu WC, Castell DO. The symptom index: a clinically important parameter of ambulatory 24 hour esophageal $\mathrm{pH}$ monitoring. Am J Gastroenterol 1988; 83: 358-61.

10 Ott DJ, Gelfand DW, Chen YM, Wu WC, Munitz HA. Predictive relationship of hiatal hernia to reflux esophagitis. Gastrointest Radiol 1985; 10: 317-20.

11 Johnson DA, Winters C, Spurling TJ, Chobanian SJ, Cattau EL. Esophageal acid sensitivity in Barrett's esophagus. J Clin Gastroenterol 1987; 9: 23-7.

12 Moraes-Fitho JP, Bettarello A. Lack of specificity of the acid perfusion test in duodenal ulcer patients. Dig Dis Sci 1974; 19: 785-90.

13 Breen $\mathrm{KJ}$, Whelan $\mathrm{G}$. The diagnosis of reflux esophagitis; an evaluation of five investigative pro- cedures. Aust NZ J Surg 1978; 48: 156-61.

14 Wiener GJ, Morgan TM, Copper JB, Wu WC, Castell DO, Sinclair JW, Richter JE. Ambulatory 24 hour oesophageal $\mathrm{pH}$ monitoring; reproducibility and variability of pH parameters. Dig Dis Sci. 1988; 33: 1127-33.

15 Yuan Y, Murphy DW, Wu WC, Castell DO. Does the esophageal $\mathrm{pH}$ probe miss events of acidic gasteroesophageal reflux (GER)? Assessment in human subjects [Abstract]. Am J Gastroenterol 1987; 82: 974(A).

16 DeMeester TR, O'Sullivan GC, Bermudez G, Midell AI, Cimochowski GE, O'Drobinak J. Esophageal function in patients with angina-type chest pain and normal coronary angiograms. Ann Surg 1982; 196: 48897.

17 Atkinson M, Bennett JR. Relationship between motor changes and pain during esophageal acid perfusion. Am J Dig Dis 1968; 13: 346-50.

18 Burns TW, Venturates SG. Esophageal motor function and response to acid perfusion in patients with symptomatic reflux esophagitis. Dig Dis Sci 1985; 30: 529-35.

19 Kjellen G, Tibbling L. Oesophageal motility during acid provoked heartburn and chest pain. Scand J Gastroenterol 1985; 20: 937-40.

20 Jones CM. Digestive tract pain. Edinburgh: MacMillan Co, 1958: 7-20.

21 Traube M, McCallum RW. Effect of acid infusion on esophageal motility in the normal esophagus [Abstract]. Clin Res 1985; 33: 756A.

22 Peters L, Maas L, Petty D, et al. Spontaneous noncardiac chest pain. Evaluation by 24 hour ambulatory esophageal motility and $\mathrm{pH}$ monitoring. Gastroenterology 1988; 94: 878-86. 